Vegueta. Anuario de la Facultad de Geografía e Historia

22 (1), 2022, 17-37

eISSN: 2341-1112

https://doi.org/10.51349/veg.2022.1.02

\title{
Historia digital: un campo en busca de identidad ${ }^{1}$
}

\author{
Digital History: A Field in Search of Identity
}

\author{
Anaclet Pons \\ Universitat de València \\ https:/ / orcid.org/0000-0001-9834-1564 \\ anaclet.pons@uv.es
}

Recibido: 22/07/2021; Revisado: 29/12/2021; Aceptado: 27/01/2022

\begin{abstract}
Resumen
¿Qué es la historia digital? ¿Cuáles son sus características? Este texto pretende aclarar en qué consiste este campo académico, presentando algunos de sus rasgos esenciales y planteando algunas dudas. Para ello, ofrece un recorrido en dos partes. Por un lado, describe someramente la genealogía de la «transdisciplina» denominada «humanidades digitales». Por otro, detalla el significado de la «historia digital», centrándose en un ejemplo -en torno a la obra del prestigioso historiador Robert Darntonque permite aclarar los resultados y los debates que ha generado. El texto concluye afirmando que en un mundo caracterizado por la desmaterialización del texto y por la abundancia de documentos, no se pueden entender nuestras sociedades ni los procesos en los que están envueltas sin prestar atención a los procesos digitales que rigen nuestras vidas y nuestro trabajo.
\end{abstract}

Palabras clave: Historiografía, Historia digital, Humanidades digitales, Robert Darnton.

\begin{abstract}
What is digital history and what are its characteristics? This article aims to clarify what constitutes this academic field, presenting some of its essential features and raising some doubts. To do so, the article offers a two-part overview. On the one hand, it briefly describes the genealogy of the «transdiscipline» known as the «digital humanities». On the other, it details the meaning of «digital history», focusing on the work of the prestigious historian Robert Darnton, thus illuminating the results and debates the

1 Este texto se enmarca en el proyecto de investigación HISMEDI: Historia, Memoria y Sociedad Digital. Nuevas formas de transmisión del pasado. La transición política a la democracia. RTI2018-093599-B-I00 MCIU/AE/FEDER-UE. Agradezco además las sugerencias de los evaluadores del artículo. En otro orden de cosas, todas las traducciones son del autor.
\end{abstract}


field has generated. The article concludes that in a world characterised by the dematerialisation of text and the abundance of documents, it is impossible to understand our societies nor the processes in which they are involved without paying attention to the digital processes that govern our lives and our work.

Keywords: Historiography, Digital History, Digital Humanities, Robert Darnton.

\begin{abstract}
Los hombres (y las mujeres) están, en efecto, llamados al dominio de las cosas. De las cosas precisamente. De las personas y de los acontecimientos de la vida somos y seremos siempre partícipes y alumnos, nunca maestros. Establecer esa distinción -entre las cosas y las personas, entre el dominio y el aprendizaje- es lo que significa ser -como lo fue Swinburne- un humanista. Hoy tenemos que intentar dominar algunas cosas nuevas. Tenemos que aprender a hacerlas y a utilizarlas. Perseguir ese objetivo nos compromete a una exigente, y por tanto humilde, aventura del conocimiento. Lo haremos convirtiéndonos de nuevo en estudiantes, un papel que, como educadores y humanistas, creo que se nos da especialmente bien (McGann, 2013, 62-63).
\end{abstract}

Estas palabras preliminares las escribió el humanista -filólogo, historiador de la literatura, estudioso de la textualidad- Jerome J. McGann hace algo más de una década, con humildad, cansado de que la mayoría de sus colegas desatendieran las tecnologías digitales y, más aún, preocupado por la general inconsciencia sobre el impacto que éstas estaba ejerciendo en el mundo de las humanidades. Dado, decía, que la totalidad de nuestra herencia está mutando a las nuevas formas electrónicas, desmaterializadas, necesitamos comprender urgentemente lo que esto significa, así como los problemas que conlleva. No hacerlo es caer en el analfabetismo digital y tal cosa nos marginaría como ciudadanos y como académicos. De lo que no le cabía ninguna duda, y así sigue siendo, es de que los costes iniciales serían elevados y la curva de aprendizaje sumamente empinada, pero eso no lo hacía menos inevitable:

¿Recuerdan la distinción marxiana entre la base y la superestructura? Recuérdenla. Nuestros conflictos ideológicos de hoy están profundamente arraigados: comercialmente, económicamente, institucionalmente. Porque esta es la cuestión, tenemos cosas útiles y prácticas que podemos y debemos hacer. Pero antes de que esas cosas sean posibles, tendremos que poner fin a la cantinela que impregna gran parte de nuestro discurso (McGANN, 2013: 53-54).

Jerome J. McGann abogaba, pues, por una «praxis de la teoría» que dejara de lado una determinada cantinela, la que se corresponde con esa actitud angelical (e ineficaz) de rechazo a cierta tecnología que tanto abundaba en las humanidades, pero al tiempo era comprensivo con el problema, consciente de las dificultades y las dudas. Por mi parte, añadiré que tales incertidumbres y perplejidades son importantes y explican el contexto en el que nos movemos.

Ante todo, ese «angelismo» es a veces una especie de defensa ante la sombría y deprimida situación del campo humanístico, que parece estar nuevamente ante la tesitura de renovarse o morir. Desde tal perspectiva, es comprensible que se diga que la salvación no está en abrazar la ciencia básica y la tecnología, fundiéndose con ellas, sino en mantenerse firmes. Porque la cuestión -suele 
afirmarse- no es oponer algo anticuado e inútil frente a lo nuevo y práctico, pues esa antinomia simplista no nos dejaría ver que la etiqueta digital arrastra con ella un determinado modelo epistemológico y unas formas concretas de representar el mundo (presente y pasado). A su vez, eso implica nuevos modelos de organizar la investigación, con objetivos distintos en muchos casos, alejados de los tradicionalmente nuestros (MounIER, 2018).

Por otra parte, hemos de reconocer que las nuevas tecnologías lo desordenan todo, planteando nuevos retos, lo cual dificulta admitirlas de buen grado. Eelco Runia suele decir, en tono provocador, que «los historiadores no piensan», pero no porque carezcan de habilidades mentales ni porque las que tienen no sean válidas, sino porque la disciplina prima clasificar las cosas y, visto así, se podría decir que «de alguna manera han perdido la capacidad de tolerar el desorden. Y «pensar», continúo, es volver las cosas del revés, no dejarlas como están, desmontarlas o, en definitiva, hacerse intencionadamente un lío» (RUNIA, 2014, $\mathrm{XI}-\mathrm{XII})$. En efecto, el lío y el desorden son monumentales, porque la historia o las humanidades digitales no son en puridad un campo específico, o al menos no lo son en la medida que, como veremos, lo que representan afecta a todos y cada uno de los campos y subcampos en que podamos clasificar una y otras. Lo digital, por decirlo así, es un enfoque (o tiene un impacto) transversal. Utilizando una metáfora paisajista, así lo describe Jo Guldi:

Las prácticas y los métodos de la historia digital están transformando parcelas aquí y allá en todo el paisaje: aquí una red neuronal, allí un modelo temático, en otro lugar un mapa o una red social, abarcando toda la gama de periodos, geografías, orientaciones e instituciones, de manera que ningún campo de la erudición histórica, por remoto que sea, está hoy demasiado lejos de algún parterre donde algún estudioso haya aplicado a sus labores una práctica asistida por ordenador (GuLDI, 2020, 328).

Por tanto, nos viene a decir esta historiadora, recorrer la historia digital, con sus vericuetos, es transitar todo el rico paisaje de espacios que constituyen la historia tradicional, siempre con la duda de si la ola digital ahogará la rica y variada campiña que tan amorosamente hemos cultivado.

\section{LA GENEALOGÍA DEL CAMPO}

Ante tal desconcierto, lo lógico sería ir de inmediato a la praxis, como diría McGann, dando una definición, señalando lo que hacen hoy los llamados historiadores digitales y explorando, en fin, cómo las nuevas tecnologías están modificando el conjunto de las prácticas de nuestra disciplina, sin olvidar los acordes y los desacuerdos. Pero tales cosas no se pueden entender sin acudir a la genealogía del asunto, que es la que explica parte del desarreglo resultante.

Lo primero, aunque ya muy reiterado, es recordar los orígenes del adjetivo digital y su uso en el presente, dado que la posición de la historia no se entiende sin aludir al marco general, el de las humanidades digitales, hasta el punto de que para algunos su separación carecería de utilidad. En efecto, este término procede del uso que de determinados instrumentos mecánicos empezaron a hacer quienes se dedicaban a la filología, y a los estudios literarios en particular, siendo su 
objeto el documento escrito, pero entendido como una secuencia alfanumérica. Con el padre Roberto Busa como referente y pionero, estos estudiosos hallaron en el uso de la informática para el análisis de textos una formidable ayuda y una extensión más o menos natural de sus métodos clásicos. De ese modo, además, en la medida en que los orígenes estuvieron en el procesamiento automático de datos lingüísticos, las preocupaciones fueron y han sido principalmente de tipo hermenéutico, orillando otras de tipo metodológico y epistemológico (FIORMONTE, 2017).

Por esta razón y por este origen, se utilizó inicialmente el término «informática humanística», refiriéndose a una asistencia mecánica para el trabajo académico, sin mayores implicaciones. Con el tiempo, no obstante, se alteró el orden de las palabras empleadas, pasando el adjetivo a ser el sustantivo y sustituyendo el vocablo «informática» por otro menos técnico, más humano, con el resultado ya conocido: humanidades digitales. El asunto, por lo demás, fue relativamente azaroso, tal como lo ha relatado John Unsworth:

El verdadero origen de ese término fue una conversación con Andrew McNeillie, el editor original del Blackwell Companion to Digital Humanities. Empezamos a hablar con él sobre ese proyecto de libro en 2001, en abril, y a finales de noviembre ya habíamos reunido a los colaboradores y estábamos discutiendo el título, para el contrato. Ray [Siemens] quería A Companion to Humanities Computing, ya que ese era el término comúnmente utilizado en ese momento; la gente de la editorial y de marketing de Blackwell quería Companion to Digitized Humanities. Yo sugerí Companion to Digital Humanities para alejarnos del énfasis en la simple digitalización (KiRSCHENBAUM, 2012).

Por tanto, el término aparece a inicios de esta centuria, con este volumen en particular, un libro que pretendía marcar un punto de inflexión reuniendo los trabajos realizados en las décadas precedentes y afirmando con ello la existencia de una disciplina con derecho propio (SCHREIBMAN et al., 2004). Ahora bien, al margen de estas consideraciones, se puede argumentar que tal variación semántica pretendía indicar que ya no se trataba de un servicio meramente técnico, sino que las nuevas herramientas empleadas se integraban indisolublemente en cierto tipo de investigaciones, generando así un esfuerzo intelectual genuino con sus propias prácticas, estándares y exploraciones teóricas. Llegado el momento, y por estas razones, se podía afirmar incluso que las tecnologías digitales estaban cambiando significativamente el modo de investigar, porque no sólo éste quedaba mediado por aquéllas, cuestionando además algunos de sus supuestos, sino que tal mediación afectaría a nuestra experiencia de la cultura y la sociedad contemporáneas, y en consecuencia a nuestra comprensión del pasado (BERRY, 2011).

Así pues, podemos decir que las humanidades digitales parten del hecho de que «los cambios trascendentales experimentados en el ámbito digital por nuestras sociedades modifican y cuestionan las condiciones de producción de los saberes», se apoyan «en el conjunto de los paradigmas, de los saberes y conocimientos propios de estas disciplinas, a la par que van movilizando herramientas y perspectivas propias del campo digital» y designan, en suma, «una "transdisciplina" portadora de los métodos, dispositivos y perspectivas heurísticas relacionadas con procesos de digitalización en el campo de las Ciencias Humanas y Sociales» (DACOS, 2011). Métodos, dispositivos y perspectivas que, por otra parte, y a pesar de su variedad, se han desarrollado y continúan ampliándose 
sobre todo en torno al campo inicial: la filología y el análisis de textos. Y este elemento no ha de orillarse, pues ha tenido algunas consecuencias que conviene considerar.

En primer lugar, el proceso de digitalización de los libros (y de otros documentos de todo tipo) ha supuesto su remediación, la posibilidad de tratar su contenido como data y, por tanto, de aplicarles herramientas acordes con ello. Tal oportunidad ha implicado una reconsideración del sentido de la filología. Como ha señalado el citado Jerome McGann, antes de la aparición del giro lingüístico, esta área era vista como una especialidad propia de eruditos dedicados a analizar exhaustivamente esos artefactos materiales que denominamos libros, sus formas y sus contenidos, su sociohistoria en definitiva. Pero a partir de ese giro los filólogos se decantaron hacia una perspectiva hermenéutica y su práctica pasó a ser conocida como la de los estudios literarios y culturales. De modo que «en el siglo $\mathrm{xx}$, el método histórico comprehensivo fue desplazado gradualmente, y el propio término "filología" cayó en desuso». En ese contexto, «los estudiosos se volcaron en hermenéuticas de diversa índole y, tras la Segunda Guerra Mundial, en los intereses metainterpretativos que se desarrollaron, de forma igualmente diversa, bajo la bandera general de la Teoría» (MCGANN, 2014: 19). Ahora bien, la aparición de los medios digitales ha invertido esa posición, hasta el punto de que su difusión y uso «está obligando a volver a la visión de la filología tradicional, en la que la erudición textual se entendía como el fundamento de todos los aspectos de los estudios literarios y culturales» (McGANN, 2014: 20).

Lo conclusión de McGann es simple. Todo el pensamiento humanista ha sido moldeado por las instituciones y la tecnología que han venido acompañando a los libros. Si esa ecología ha sido transformada, comprender los nuevos medios y entender cómo afectan a esa ecología textual ha de ser el punto de partida para cualquier enfoque práctico de las humanidades digitales. Para hacerlo, «la erudición textual y editorial, a menudo marginada en los estudios humanísticos como un ámbito estrechamente técnico, debería volver a situarse en el centro de la atención humanista». No es que nuestro trabajo no tenga que ser recompuesto bajo nuevas claves, pero el fundamento de la investigación humanista se mantiene. Por esa razón, cuando tratamos de explotar los entornos electrónicos, hemos de pensar en ellos $-y$, de hecho, lo hacemos- en términos filológicos tradicionales. Es decir, hay que saber cómo funcionan los textos, entendiendo «que la erudición tuvo una vez un nombre con el que conjurarlo: filología» (McGANN, 2014: 2).

Puede decirse que, a grandes rasgos, la propuesta que formula McGann se ha realizado, de modo que esa filología ha pasado a ser el referente fundamental de las humanidades digitales, sustituyendo o afectando a buena parte de esa Theory. Esto tiene varias consecuencias, y de diversa índole, de las que señalaré dos. La primera tiene que ver con el papel que va a desempeñar nuestra disciplina, la historia, dentro del conjunto, algo que ha expresado de forma inmejorable nuestro colega Tim Hitchcock:

Las Humanidades Digitales son una bestia curiosa. Tiendo a pensar en ella como en una especie de caballo de pega, con la crítica, la lectura distante y la teoría literaria ocupando la parte delantera, todos relinchando y pataleando en la MLA [Modern Language Association] cada año (y en Los Angeles Review of Books), mientras que la historia, la geografía y la biblioteconomía están atascadas en la parte trasera, haciendo el duro trabajo de crear nuevos recursos digitales y probar nuevas herramientas. Como me encuentro en la parte de atrás de esta componenda, paso 
gran parte de mi tiempo esperando que los airados debates de la parte delantera no provoquen demasiados trastornos en la parte trasera (Нгтснсоск, 2016).

Pero hay una segunda consecuencia. Aunque Jerome McGann no siempre se muestre muy de acuerdo con la idea de que el humanista necesite una gran actualización ni en que necesitemos nuevos protocolos que reemplacen los tradicionalmente usados en las humanidades, lo cierto es que él mismo reconoce, como hemos adelantado, que la totalidad de nuestro archivo heredado de obras culturales está mutando a formas electrónicas. Y el principal efecto, como he mencionado, es que los textos son -o se transforman mediante su digitalización en- data y, por tanto, permiten tratamientos distintos, sobre todo cuantitativos. Eso es en buena medida lo que significa aquello que he adelantado sobre cómo lo digital arrastra un determinado modelo epistemológico y unas formas concretas de representar el presente y el pasado.

Este fenómeno tiene un nombre, Big Data, y no sólo se refiere a que los conjuntos de datos disponibles sean ahora muy grandes, masivos, sino también, y en consonancia, a que han aparecido nuevas herramientas -y se aplican otros procedimientos- para manipularlos y analizarlos. Por tanto, quien los utiliza no se conforma con las habilidades tradicionales, porque la propia existencia de esos data produce un cambio en las formas de abordar la investigación y en los métodos utilizados para analizarla. Se trata, por otra parte, de un problema general, pues cualquier herramienta no es simplemente una ayuda para medir una determinada actividad, sino que configura la realidad que mide (BOYD y CRAWFORD, 2012).

En efecto, el primer cambio es de escala, en la medida en que las posibilidades cuantitativas que ahora se abren tienen consecuencias cualitativas. Viktor MayerSchönberger y Kenneth Cukier (2013) lo vieron perfectamente cuando señalaron que, al igual que el telescopio y el microscopio ofrecieron perspectivas novedosas, las técnicas de recopilación y análisis de enormes volúmenes de datos nos llevan a ver el mundo de una forma diferente. Y esa forma nos conduce a uno de los elementos característicos de ese cambio cualitativo: el análisis correlacional. En lugar de la tradicional indagación en las causalidades, la conversión en datos de todo lo que nos rodea nos lleva a buscar y a descubrir pautas y correlaciones en esos datos. Es un modelo predictivo que no ofrece una explicación del porqué, sino sobre todo del qué.

Así pues, como diría Bruno Latour, «si cambias los instrumentos, cambiarás toda la teoría social que los acompaña» (LATOUR, 2009: 155). Y eso mismo ha ocurrido con el objeto clásico de la filología: el análisis de textos. Pensemos, por ejemplo, en los trabajos del estudioso más citado y utilizado en este campo: Franco Moretti y su propuesta de «lectura distante». Para este filólogo, cuando nuestro objeto de estudio es un volumen masivo de textos, a escala mundial, podemos optar por dos puntos de vista diferentes: una «lectura directa», lo que supone una enorme reducción de lo que estudiamos, manejando un canon muy reducido al que damos un tratamiento muy solemne; o una lectura distante, que invierte la perspectiva anterior, que es contraria a la idea de historiografía nacional y que es imprescindible cuando queremos ir más allá de ese canon.

Moretti defiende esta segunda perspectiva, ya que el nuevo entorno digital le permite utilizar la mirada telescópica, descubriendo cosas que estaban ahí y que antes prácticamente nadie había visto. Por supuesto, esa idea de lectura distante es cuantitativa y, por esa misma razón, puede decirse que es más correlacional 
que causal o que, en otros términos, muestra preferencia por la explicación, por las formas, por los patrones y por las estructuras profundas, en detrimento de la comprensión. La razón es que «la ambición es ahora directamente proporcional a la distancia con el texto; cuanto más ambicioso sea el proyecto, mayor deberá ser la distancia» (MORETTI, 2000: 67).

Para Moretti, la novedad más importante ocurrida en su campo -pero no sólo en el suyo- es el actual tamaño del archivo literario. Si antes, por ejemplo, los estudiosos del siglo XIX trabajaban a partir de un par de cientos de novelas, ahora pueden analizar decenas de miles y, pronto, centenares de miles. Para la historia literaria cuantitativa es como tener un telescopio que nos hace ver galaxias completamente nuevas, con los efectos correspondientes: «esto ha tenido un efecto importante en la historia literaria, obviamente, pero también en la metodología crítica; porque, cuando trabajamos con 200 mil novelas en lugar de 200, no estamos haciendo lo mismo, mil veces más grande; estamos haciendo una cosa diferente». Es decir, «la nueva escala cambia nuestra relación con nuestro objeto, y de hecho cambia el objeto mismo» (MoretTI, 2017: 1).

Llegados a este punto, es lógico que este cambio de perspectiva haya originado críticas, en un doble sentido. Por un lado, por lo que respecta al método. Si recordamos la evolución trazada por McGann, entenderemos que quienes han practicado una lectura cercana, aplicando la hermenéutica tradicional, consideren poco afortunada esta otra opción. Stanley Fish, por ejemplo, describe su análisis el siguiente modo: «primero la hipótesis interpretativa y luego el patrón formal, que alcanza el estatus de perceptible sólo porque una interpretación ya existente lo está eligiendo». ¿Qué hacen en cambio los humanistas digitales, y Moretti en particular? Algo muy distinto, pues primero barajarían los datos y luego se plantearían si ese tratamiento conduce a alguna hipótesis interpretativa. De ese modo, la capacidad de la herramienta determina el método empleado: «tiene a su disposición una increíble potencia de cálculo que puede llamar la atención de los analistas sobre patrones de similitud y diferencia indetectables por el ojo del lector humano. Como los patrones son indetectables, no se sabe de antemano de qué se trata y no se puede comenzar la búsqueda asistida por ordenador (llamada minería de textos) de forma motivada, es decir, dirigida interpretativamente. No se sabe qué se busca ni por qué se busca». Su conclusión es demoledora, pues entiende que las humanidades digitales son el opuesto del tipo de análisis literario que él y otros preconizan, «una crítica que reduce el significado a los significados diseñados por un autor, una crítica que generaliza a partir de un texto tan pequeño como media línea, una crítica que insiste en la distinción entre lo verdadero y lo falso, entre lo que es relevante y lo que es ruido, entre lo que es serio y lo que es mero juego. No hay nada lúdico en lo que hago o intento hacer. Tengo mucho a lo que responder» (FISH, 2012).

A esta primera crítica se añade otra, que es su consecuencia más radical: además de contravenir la hermenéutica de los textos, o quizá por eso mismo, los proyectos de humanidades digitales ofrecen pocos resultados significativos, sobre todo si se los compara con los de la hermenéutica tradicional. Es lo que señala uno de los críticos más recientes y polémicos, Timothy Brennan, cuando se pregunta: «¿qué han conseguido exactamente las humanidades digitales?». No demasiado, contesta, porque, por un lado, «los problemas interpretativos que resuelven los ordenadores no son los que han dejado perplejos a los críticos a lo largo del tiempo»y, por otro, «la tecnología exige que se le pregunte sólo 
lo que puede responder, cambiando las preguntas para ajustarse a sus propias limitaciones. Estas resultan ser poco interesantes. Como suele ocurrir en los esquemas computacionales, los investigadores de HD reducen sus preguntas para hacerlas manejables» (BRENNAN, 2017).

Aunque contiene una parte de verdad, esta crítica resulta excesiva. Como ha señalado el propio Franco Moretti en diversas ocasiones (Moretti, 2016), es cierto que, por lo general, los resultados han estado por debajo de las expectativas generadas y también lo es que parte del problema radica en que las humanidades digitales se proclaman tan revolucionarias que, a la postre, decepcionan al no producir suficientes muestras de relevancia. Pero eso no significa que no haya muchos y variados ejemplos que manifiestan la existencia de propuestas valiosas, como mencionaré más adelante.

¿Cuál es, pues, el problema? Tal y como lo he planteado, mi impresión es que las humanidades digitales se han definido (sobre todo) a partir de cuestiones textuales y que, en consecuencia, en los debates que han surgido en torno a ellas se discute sobre asuntos propiamente literarios, sobre los métodos y las perspectivas de su modelo crítico. De modo que, a la postre, todo pueda ser visto como un conflicto de interpretaciones, a favor o en contra, a veces sin término medio. Un conflicto en el que la lectura atenta, cercana, siempre será vista como la propia del humanista. Y esta trayectoria y estos debates han acabado contaminando la discusión y las prácticas de aquellas disciplinas que han llegado después, en particular la historia.

En ese sentido podemos decir, simplificando en exceso, que los historiadores han manifestado diversas reacciones, en sentidos más o menos contrapuestos. Entre las favorables, por ejemplo, una de ellas tiene que ver con la cuestión de la perspectiva, el cambio de escala, ligado como ya he indicado a la aparición de los datos masivos, al Big data. Es lo que han propuesto, por ejemplo, Jo Guldi y David Armitage. Su planteamiento, como es sabido, se inicia con un asunto distinto, el de la pérdida de protagonismo de la historia a la hora de mostrar los grandes procesos de la humanidad. Ello se debería a que muchos historiadores han desertado de la longue durée de Braudel, decantándose por investigaciones sobre temas minúsculos, con metodologías que favorecen una lectura intensiva y exhaustiva de los documentos. Así pues, para recuperar aquellos estudios a largo plazo, una solución es el uso de los big data, es decir, aplicar nuevas herramientas digitales para manejar la enorme proliferación de cifras, documentos, información $\mathrm{y}$, en definitiva, de archivos. De ese modo, «cuanto más se expandan, se critiquen y se examinen históricamente los datos, más posibilidades habrá de que surjan nuevas y reveladoras correlaciones» (GULDI y ARMITAGE, 2014: 184). A partir de esas correlaciones, podremos crear metarrelatos multicausales, comparando distintos puntos de vista sociales, culturales o de cualquier otro tipo.

Es algo semejante a lo que Shawn Graham, Ian Milligan y Scott Weingart señalan en su defensa del uso del «macroscopio» para explorar los datos, con su llamada a entender cómo los medios digitales y sus algoritmos están afectando a los proyectos tradicionales de investigación humanista (GRAHAM et al., 2015). Y también es similar, por ejemplo, a lo que plantea Patrick Manning con su proyecto "Collaborative for Historical Information and Analysis», en el que propone digitalizar una creciente porción de la documentación histórica existente, vinculando así registros dispersos por todo el mundo, para obtener con ello patrones e interacciones sociales a escala global de los últimos cuatro siglos 
(MANNING, 2013).

Todo ello, por supuesto, podemos relacionarlo con la lectura distante de Moretti. De modo que muchos de los reproches a este cambio de escala y al tratamiento cuantitativo los acaba recibiendo el propio Moretti. Es lo que ocurre, por ejemplo, cuando Carlo Ginzburg alude a este último para decir que «mientras más grande es la distancia respecto de las fuentes primarias, mayor es el riesgo de quedar atrapados en las hipótesis propuestas o por los intermediarios, o por nosotros mismos, como actualmente sucede. En otras palabras, nos arriesgamos a encontrar sólo aquello que estamos buscando, pero nada más» (GINZBURG, 2013: 21). En suma, el intermediario, las tecnologías, no pueden sustituir al humanista avezado, ni lo cuantitativo a lo cualitativo, ni lo macro a lo micro. Además, esa abundancia de fuentes e información puede incluso no resultar beneficiosa:

«creo que la investigación pueda ser perjudicada por un exceso de documentación. Cuando se está inundado por una cantidad enorme de datos es difícil (si no imposible) identificar aquellos verdaderamente significativos. Pero quien se confía de un método como de una ganzúa capaz de abrir todas las puertas quedará inevitablemente desilusionado. Métodos del género no existen, o mejor: existen, pero llevan a descubrir solamente banalidades» (GINZBURG, 2004: 20).

Desde esta perspectiva, es lógico que muchos, incluso algunos de los que practican las humanidades digitales, vean esas preocupaciones e inquietudes, ligadas al análisis cuantitativo de textos y al cambio de escala, como algo ajeno al quehacer habitual del historiador, cuya investigación va más allá de las definiciones estables o los cálculos matemáticos. Su trabajo, como el de los humanistas, requeriría de metodologías y herramientas creadas por y para ellos, no de aplicaciones informáticas generadas en otro lugar. De ahí que propongan separarse de esas humanidades y reclamar otros objetos propios, ya sea «reunir, preservar y presentar el pasado en la web» o explorar la cartografía digital (RoBERSTON, 2016). De ese modo, evitaríamos algunos inconvenientes, pues llamar a nuestro trabajo humanidades digitales habría hecho que nos fuera más difícil hacerlo comprensible y respetable en el contexto disciplinario (SCHEINFELDT, 2014).

Ahora bien, las críticas, desde fuera o desde dentro del propio campo, no deben ocultar que, más allá de las herramientas y los métodos, con sus virtudes y defectos, hay muchas investigaciones en historia y en humanidades digitales que son relevantes y valiosas (ARGUING, 2017).

\section{UNA CIERTA DEFINICIÓN, CON UN EJEMPLO}

Hasta aquí he mostrado el origen del campo y sus peculiaridades, amén de algunas reacciones en uno $u$ otro sentido, un contexto que sirve para indicar que la historia digital ha sido una parte (pequeña quizá, pero bastante ruidosa) de ese todo, reclamando en ocasiones una identidad propia (SALMI, 2020) y diluyéndose, en otras, dentro del más amplio término de las humanidades digitales (BLANEY et al., 2021), con las lógicas dudas sobre el lugar de pertenencia. De hecho, como ha señalado Adam CRYMBLE (2021), los historiadores hemos tardado bastante en reconocer hasta qué punto nuestro campo ha sido afectado por el auge transfor- 
mador del ordenador. De ahí que el término haya tardado bastante en acuñarse (AYERs, 1999) y algunos años más en ser definido. Habitualmente, se entiende que «la historia digital es un enfoque para examinar y representar el pasado que trabaja con las nuevas tecnologías de comunicación del ordenador, la red de Internet y los sistemas de software». De ese modo, por un lado «es un ámbito abierto de producción y comunicación académicas, que abarca el desarrollo de nuevos materiales para cursos y colecciones de datos». Por otro, «es un enfoque metodológico enmarcado en el poder hipertextual de estas tecnologías para crear, definir, consultar y anotar asociaciones en el registro humano del pasado». En suma, cuando hacemos historia digital, creamos «un marco, una ontología, a través de la tecnología, para que la gente experimente, lea y siga un argumento sobre un problema histórico» (Thomas III, 2008). Visto así, como decía, no se trata tanto (o sólo) de un campo específico cuanto de una perspectiva transversal. Ello es así porque quien hace historia digital está haciendo historia social o cultural o económica, de modo que lo que le diferencia son esas tecnologías específicas que emplea. Ahora bien ¿son éstas algo exclusivo de los historiadores digitales? ¿Qué es lo opuesto a la historia digital? ¿La historia social o la política; acaso la del género o la microhistoria? No, más bien podríamos decir que su opuesto exacto sería la historia analógica. Pero ese adjetivo no lo utilizamos para describir muestro trabajo de hace algunas décadas. Y no lo empleamos porque eso no nos diferenciaba a unos de otros, todos éramos analógicos. Por la misma razón, podríamos decir que ahora todos somos digitales. Aunque con algún matiz, puesto que, si bien todos hacemos historia digitalmente, pues no podemos escapar del contexto en el que nos movemos, no todos somos historiadores plenamente digitales. Es decir, todo historiador es digital, en el sentido de que hasta cierto punto todos usan medios digitales en algún momento, para recopilar información, para escribir, para publicar o para comunicarse. Sin embargo, no todos son historiadores digitales en el sentido de que no todos emplean las herramientas y técnicas específicas que a éstos les caracterizan.

Digámoslo de otro modo. Como señaló John UNSWORTH (2013: 36-37) refiriéndose a las humanidades digitales, es importante distinguir una herramienta de los distintos usos que se pueden hacer de ella, aunque sólo sea para evaluar su eficacia. Un martillo, como sabemos, es un muy bueno para insertar un clavo, mientras que un destornillador no lo es tanto, aunque sea un arma bastante eficaz y, por ejemplo, un pésimo instrumento musical. Y en ese sentido ahora tenemos un instrumento denominado ordenador que es una máquina de uso generalizado que permite actividades muy diversas, las cuales conviene diferenciar. Entre esas muchas cosas que permite hacer -más allá de escribir, enviar correos o navegar por la red...-, está lo que Unsworth denomina computación para las humanidades (o para la historia), en la que se utiliza como herramienta para modelar los datos y nuestra comprensión de los mismos. Por tanto, una cosa sería el uso común de tal herramienta y otra distinta utilizarla de manera aplicada. Diferente cuestión es si tal distinción está o no llamada a desaparecer, en la medida en que ese espectro tecnológico acabe por imponerse y, por tanto, el adjetivo digital, por extendido, carezca ya de sentido (WINTERS, 2018).

Ahora bien, la definición del campo no importa demasiado, porque por muy clara que esté no todos entienden lo mismo cuando la practican. Así que, como dice el mencionado Adam Crymble, la historia digital no necesita definiciones, sino ejemplos. Y no faltan, más bien lo contrario. A juicio de este historiador, no 
hay ninguna otra disciplina que haya invertido más energía y reflexión en ese empeño, más allá de que el historiador común siga «estando firmemente atado a las tradiciones académicas: polvo en los archivos y no bytes en la memoria del ordenador» (CRYMBLE, 2021: 1).

Conectemos esta idea con la anterior, con la de que todos usamos las mismas herramientas, pero no para lo mismo, y veamos un ejemplo. Antes de entrar en materia, no obstante, conviene remarcar un par de aspectos. El primero supone reconocer que ya lo he tratado con anterioridad, aunque de forma sumaria (Pons, 2008a), pero creo que merece mayor detenimiento, con lo que se pueden incorporar referencias y discusiones que han ido apareciendo en estos años. El segundo implica recordar que hay diversas prácticas características de la historia digital (ARGUING, 2017), más allá de lo que significa y representa el análisis textual. Por tanto, es solamente un ejemplo, escogido por su relevancia académica, poco común.

Con tales salvedades, pues, retomo el caso en cuestión porque resulta muy significativo en varios aspectos, de forma y de fondo, como se verá de inmediato. Por un lado, tenemos a un historiador consagrado, Robert Darnton, cuya carrera académica se ha construido en buena medida a partir de un fondo documental muy concreto: el de la Sociéte Typographique de Neuchâtel (STN). Aunque no ha sido la única fuente que ha nutrido sus escritos, sí ha sido fundamental en la mayoría de ellos, desde sus inicios hasta la actualidad. Y ello porque estos archivos «son los únicos documentos de una editorial del siglo XVIII que han sobrevivido casi intactos y son lo suficientemente amplios (unas 50.000 cartas) como para revelar la historia interna de la edición pirata y de la edición en general» (DARNTON, 2021: 6). En efecto, su investigación de 1979 sobre el negocio de la ilustración ya se remontaba «a 1965, cuando comencé a explorar los archivos de la Societe Typographique de Neuchatel y las colecciones Chambre Syndicale y Anisson-Duperron de la Bibliothèque Nationale» (DARnTON, 2006: xxv). Por tanto, toda una vida dedicada a este asunto, con un punto y final recién anunciado: «después de haber trabajado en este material durante más de cincuenta años, espero hacer justicia a su riqueza. Aunque este libro pone fin a mi investigación, no pretende llegar a nada comparable a un fondo, pues la historia no tiene fondo y en esta obra sólo espero sondear sus profundidades» (DARNTON, 2021: 6).

Por otro lado, tenemos un proyecto de humanidades digitales sobre ese mismo archivo: The French Book Trade in Enlightenment Europe Mapping the Trade of the Société Typographique de Neuchâtel, 1769-1794 (FRENCH, 2012). En este caso, se trata de una base de datos, una surgida hacia 2004 y materializada en 2012. El proyecto estuvo dirigido por el profesor Simon Burrows, ayudado inicialmente por: el entonces investigador posdoctoral Mark Curran -«que soportó la mayor parte del trabajo de transcripción, interpretación y registro de los datos de archivo, muchos de ellos extraídos de los áridos y voluminosos registros contables»; el «impresionante trabajo del Dr. Vincent Hiribarren», a cargo de los mapas del proyecto y responsable «de la edición final del contenido, del acabado y de la mejora de la interfaz de usuario»; si bien el diseño correspondió a Amyas (Henry) Merivale, con su «hermosa red de enlaces»; partiendo de «las iniciales instrucciones de diseño» en cuanto a estructura y edición de los datos que propuso Sarah Kattau; sin olvidar la asistencia de una estudiante de doctorado, Louise Seaward (FRENCH, 2012; DARNTON, 2012).

Esta es una primera diferencia sensible, relativa a lo que es una y otra forma 
de abordar una investigación, sea la «clásica» o la «digital»: el trabajo individual; el de un grupo. En consecuencia, también lo es la forma de afrontar el material. Por un lado, tenemos a un investigador que comenzó a estudiar ese archivo en 1965:

Desde entonces, he pasado catorce veranos y un invierno leyendo casi todas sus cincuenta mil cartas y el material complementario de los libros de cuentas del STN. Ha sido un largo camino, pero no una penalidad. Neuchâtel es una hermosa ciudad al pie de los montes Jura, con vistas a un precioso lago bordeado de viñedos. Los neuchatelenses son gente maravillosa y acogedora. Hice muchos amigos entre ellos, pasé muchas horas felices caminando con ellos de prado en prado a lo largo de las crestas del Jura, disfruté de innumerables comidas en sus casas y vi crecer a mis hijos con los suyos durante las constantes visitas a lo largo de cincuenta años (DARNTON, 2018: $\mathrm{X}-\mathrm{XI})$.

Frente a esta lectura intensa, pausada y dilatada, tenemos un equipo de investigadores y técnicos que leen la documentación para alimentar una base de datos, la cual maneja unos 400 mil ejemplares de unos cuatro mil libros que circulan por toda Europa, con todos los metadatos asociados, y es presentada con una interfaz web utilizando la tecnología GIS. Es, pues, algo totalmente distinto a lo que hizo Darnton, algo que se propone porque es posible hacerlo, dado que tal opción no estaba disponible en 1965, y que se convierte en una opción metodológica alternativa. En efecto, el cambio producido desde finales del pasado siglo hizo «que los investigadores pudieran manipular sus herramientas cartográficas para alinearlas con sus propias preguntas de investigación y no al revés. Los mapas dejaron de ser ilustraciones y se convirtieron en representaciones generativas para la lectura, además de producir datos históricos». De ese modo, el FBTEE proporciona:

\begin{abstract}
datos estadísticos geo-temporales sobre el movimiento de libros, conectando tiempos y lugares de producción, intercambio y consumo (calibrados hasta los días concretos, las ciudades y los clientes) con el fin de trazar el movimiento de libros entre un editor y sus clientes mayoristas y minoristas de toda Europa. En particular, se traza el movimiento de libros comercializados por una única editorial suiza, la Societe Typographique de Neuchâtel (STN). También permite agrupar y analizar la distribución de los libros de la STN (y, por ende, de las ideas) por temas, géneros, autores, idiomas originales, orígenes de publicación y lugares, así como crear subconjuntos personalizados para muestrear secciones del comercio de libros o compensar los sesgos de los datos. Como resultado, las herramientas del FBTEE ofrecen un método digital detallado y transferible para estudiar la transferencia de ideas y culturas a lo largo de toda una era impresa delimitada, permitiendo a los investigadores cartografiar, visualizar, comparar, analizar y correlacionar tendencias y patrones en la producción, difusión y recepción de obras impresas. Los autores, los tropos literarios, los géneros y las ideas pueden analizarse de este modo a través del tiempo y el espacio (BurRows et al., 2016: 261-262).
\end{abstract}

En suma, Burrows y Curran entendían que ese archivo era demasiado grande y complejo para que pudiera manejarlo adecuadamente un único historiador a la antigua usanza y que, por el contrario, se necesitaba un equipo de estudiosos que, con la ayuda de la máquina, lo convirtieran en una base de datos legible. No puede extrañar, por tanto, que no sólo se leyera la documentación de otro modo, sino que no se leyera exactamente la misma ni que, en última instancia, los resultados acabaran por diferir. 
No obstante, para entender el impacto hemos de recordar la importancia del tema. Como ya he indicado en otro lugar, el asunto tiene una larga y significativa trayectoria académica (Pons, 2018a). Basta con retomar las palabras introductorias que Darnton escribió en 1995 para su libro Los best sellers prohibidos en Francia antes de la Revolución:

Las grandes preguntas de la historia resultan muchas veces inmanejables. ¿Qué es lo que causa una revolución? ¿Por qué cambian los sistemas de valores? ¿Cómo influye la opinión pública en los acontecimientos? Este libro se propone enfrentar estas preguntas a partir de otro tipo de interrogante, que pueda ser respondido: ¿qué leían los franceses en el siglo xVIII? En el transcurso de este estudio ha de quedar claro cómo es posible que esa pequeña pregunta sea capaz de despejar las grandes preguntas. Ahora sólo quisiera plantearlo y señalar que también esto tiene una historia. Daniel Mornet lo planteó hace ochenta y tres años y lo convirtió en el punto de partida de una amplia investigación sobre los orígenes intelectuales de la Revolución Francesa (DARNTON, 2008: 11).

Gracias a los fondos de la STN, Darnton centraba su estudio en algo que Mornet había dejado de lado, la literatura ilegal, con una conclusión bien conocida: su gran difusión fue devastadora para la monarquía, pues con ello perdió «la larga pelea por controlar a la opinión pública. Había perdido su legitimidad» (DARNTON, 2008: 370). Es decir, Francia se habría visto inundada por libros prohibidos (ya fueran filosóficos o simples libelos) que atacaban las instituciones básicas, en particular a las principales figuras de la Corte. Esos impresos, por otra parte, provenían de imprentas cercanas a su frontera oriental, de entre las cuales la de la STN puede tomarse como un ejemplo bien representativo. Tal fue la conclusión que extrajo de su lectura minuciosa de las cartas de sus clientes, sobre todo de los habituales, y de los pedidos que esas misivas transmitían. Para Darnton, los títulos demandados equivalían a libros enviados o al menos a los que tenían más demanda, de modo que se podía conjeturar sobre cuáles eran los libros más vendidos y, asimismo, cuáles los más leídos en las décadas previas a la Revolución. Y esa conjetura era posible porque, a su parecer, la STN era representativa, dado que todos los mayoristas comerciaban más o menos con lo mismo: «llegó a existir una especie de fondo invisible y flotante a todo lo largo del área fronteriza de Francia, desde los Países Bajos hasta Suiza. Estaba al alcance de todos los grandes editores mayoristas; y al entrar sus pedidos con uno o dos de ellos, un minorista en Francia podía conseguir virtualmente todo lo que le diera la gana» (DARNTON, 2008: 99). De ese modo, los editores se intercambiaban las existencias como parte de un sistema de reciprocidad, para reducir el riesgo y mantener un inventario diversificado.

Todo eso, o buena parte de ello, es lo que se puso en cuestión desde el principio, afectando -como no podía ser de otro modo- a la columna central de las tesis de Darnton. Y así, aunque Simon Burrows ya había anticipado previamente algunas dudas sobre el trabajo de este último (PONS, 2018a: 45), fue la presentación de la base de datos, con los comentarios que la acompañaban, lo que movió a Darnton a responder. A su parecer, el problema del análisis que ahora se presentaba provenía de utilizar las estadísticas basadas en las ventas, pues a su juicio no eran tan representativas como la demanda de los clientes fijos del editor que él había estudiado. Por tanto, el atractivo de esas estadísticas quedaba restringido sobre todo al hecho de su volumen -el de que cubrieran un territorio muy amplio-, pero poco más, y en última instancia desvirtuaban el resultado: en resumen, decía, 
la Europa de la Ilustración, según las estadísticas del FBTEE, es una Europa sin mucha Ilustración (DARNTON, 2012).

La inmediata réplica de Burrows (2012), fue más directa si cabe. ¿Qué es más importante en la historia cultural -decía-: la oferta o la demanda? ¿Lo que la gente quiere leer o lo que realmente llega a leer? La cuestión es importante, añadía, porque aunque el STN afirmara que podía suministrar casi cualquier libro procedente de cualquier lugar, eso no era cierto. La realidad, concluía, es que comercializaba principalmente un stock limitado de ediciones (en su mayoría) suizas. $Y$, en efecto, la bases de datos -y su sistema taxonómico de palabras clave para clasificar los libros- nos devuelve una imagen en la que, por ejemplo, Voltaire está poco representado en su archivo y en la que, en cambio, las obras literarias no filosóficas, la historia, las obras religiosas, los libros escolares y la literatura de viajes suponen más de la mitad de los libros que distribuía. Lo cual, en última instancia, permitía a Burrows defender que aquello era un tipo particular de Ilustración, distinta de la imagen habitual. Todo ello, pues, a partir de la utilización de un método (cualitativo) u otro (cuantitativo) y del uso de la oferta o la demanda. Como terció Mark Curran poco después, respondiendo indirectamente a Darnton: «si un libro inexistente nunca se envía a un librero atípico, ¿podría causar una revolución?» (CURRAN, 2013: 89).

No extrañará, pues, a juzgar por lo anterior, que el tono de los intercambios académicos subiera amablemente. En 2015, por ejemplo, Darnton entró aún más en el terreno del supuesto adversario, presentando su propia plataforma digital basada en el STN: «A Literary Tour de France» (DARNTON, 2015a). Una vez más, este historiador insiste en sus tesis y en el valor incomparable de la fuente (STN), con tres elementos fundamentales: pedidos, correspondencia y libros de cuentas. Ahora, en la web, «he elegido una muestra de los clientes más importantes de la STN, he transcrito sus expedientes, he recopilado estadísticas de sus pedidos, he añadido transcripciones de expedientes de los intermediarios del comercio de libros, he trazado rutas comerciales, he proporcionado información sobre las condiciones sociales y económicas de cada una de las ciudades y he digitalizado todos los manuscritos originales» (DARNTON, 2015b: 513). A la postre, el texto de presentación que redactó Darnton reitera lo ya dicho -aunque sólo menciona una vez la base de datos del FBTEE- y aclara algunos aspectos, para concluir señalando: «incluso cuando no los atendía, los pedidos que el STN recibía de sus clientes constituyen la mejor fuente para descubrir cuál era la demanda de literatura francesa en vísperas de la Revolución. La mejor fuente disponible» (DARNTON, 2015b: 526).

Como en anteriores ocasiones, el debate continuó en paralelo en la revista French History and Civilization, primero con un texto de Burrows sobre un conocido librero (Burrows, 2015) y luego, pasado un tiempo, con otro del mismo autor (BuRROws, 2017a) y con un intercambio entre ambos con un apartado propio titulado «Disputes: Robert Darnton and Simon Burrows». Por supuesto, tal disputa fue cordial, aunque no por ello menos profunda. Darnton, por ejemplo, dice de pasada que «Burrows cometió un error fundamental en su investigación [sobre ese aludido librero], y yo soy en parte responsable de ello», de modo que «llegó a una conclusión que es lo contrario de lo que indican las pruebas» (DARNTON, 2017: 207-208). Por su parte, Burrows se defiende enérgicamente, lamentando que malinterprete su estudio y trivialice sus conclusiones: «desgraciadamente, Darnton no distingue a qué conclusión se refiere ni aclara cuál debería ser la 
conclusión "opuesta" correcta (y aquí me confieso realmente confundido: no tengo ni idea de lo que podría haber pretendido). Su silencio es significativo. Implica la existencia de algún error fundamental de interpretación histórica por mi parte sin indicar cuál podría ser. Yo sostengo que no hay ninguno» (Burrows, 2017b: 215).

Para no extender el debate, se puede decir que concluye con los siguientes libros de todos ellos. Robert Darntom ofrece ya un relato más matizado de algunos aspectos colaterales en 2018 con A Literary Tour de France, que complementa la citada plataforma digital, rebajando el peso que habrían tenido elementos como el materialismo, el ateísmo o las cuestiones sexuales y pornográficas. Y ese mismo año aparecen los volúmenes de Burrows y Curran, centrados en buena medida en lo que Darnton había orillado, los numerosos libros de cuentas que la STN llevaba. De hecho, el descubrimiento más sorprendente del proyecto FBTEE había sido lo local que era su negocio, cuestionado así que sus envíos pudieran ser ampliamente representativos de los hábitos de lectura franceses o francófonos. Como señala Mark Curran, «si la STN sólo vendía libros suizos, ¿pueden sus archivos decirnos mucho sobre el curso más amplio de la historia europea? (...) ¿una fuente representativa y un atajo para conocer los gustos de lectura europeos en vísperas de la revolución francesa? No es probable» (CURRAN, 2018: 8-9). Pero, además, la base de datos cuestiona en algunos aspectos fundamentales lo dicho por Darnton sobre la naturaleza de la Ilustración en vísperas de la Revolución Francesa, así como, en general, sobre «el valor de los estrechos enfoques académicos obsesionados con un pequeño grupo de grands hommes y sus ingeniosos escritos» (Curran, 2018: 11). Una hipótesis, en fin, que no puede separarse del método empleado, como señala Burrows:

En consecuencia, este libro reflexiona sobre el desarrollo y la aplicación de nuevas tecnologías y metodologías. Es el resultado de un proyecto digital singularmente rico para cartografiar la difusión de la imprenta en la Europa del siglo xVIII, y explica los obstáculos y desafíos inherentes a nuestras fuentes y métodos y cómo se superaron. Es de esperar que el caleidoscopio de la cultura impresa del siglo XVIII y los enfoques digitales del siglo XXI que ofrece sean a la vez esclarecedores y enriquecedores. Ya que promete tanto una nueva puerta de entrada al estudio de la cultura global a través de la época de la imprenta como nuevas perspectivas sobre la Ilustración (Burrows, 2018: 6).

El colofón, por supuesto, es la última obra de Darnton, elegante como todas las anteriores, con la que cierra su dedicación académica al asunto. En ella no hay ni rastro de los citados contrincantes, aunque bien es cierto que las referencias bibliográficas -no así las notas- son escasas. Pero desprende una cierta desazón en sus líneas finales cuando, tras agradecer la ayuda que durante tantos años le han prestado bibliotecarios y archiveros acarreándole libros y documentos, dice: «¿Cómo extraer pistas de ellos? ¿Cómo construir la historia a partir de los rastros en el papel? Este libro es el resultado. Espero que tenga algo que decir a los lectores de la era digital» (DARNTON, 2021: 300).

\section{CODA}

El ejemplo anterior es altamente ilustrativo por varias razones, todas las 
cuales nos ofrecen diversas ventajas y algún ligero inconveniente. Lo es ante todo porque afecta a un célebre historiador y a casi toda su obra; y también porque alude a un objeto muy conocido y debatido, uno de los temas centrales de la modernidad, la naturaleza de la Ilustración. En ese sentido, como ha señalado Burrows, va mucho más allá de los estudios de Darnton e incide sustancialmente, por ejemplo, en los debates surgidos en torno a la no menos célebre obra de Jonathan Israel, entre otros autores (BuRRows, 2018: 7-15). Esos dos elementos, al combinarse, tienen la ventaja de mostrar que las herramientas digitales no son un mero pasatiempo y que su empleo puede reorientar determinadas asunciones y debates. Además, en esta ocasión, el autor con el que se polemiza, Robert Danton, no puede considerarse un defensor a ultranza de los métodos «analógicos», dado que a lo largo de su trayectoria ha demostrado un claro convencimiento del valor de la digitalización y un uso franco de la misma (DARNTON, 2010).

Pero también es cierto que los nuevos métodos, y en particular sus contribuciones, no siempre son bien recibidos. ¿Acaso la máquina puede proporcionar una alternativa a la lectura atenta del historiador? Yo diría que no se trata de si mejora o no nuestro trabajo artesano, sino de si nos permite ver las cosas de otro modo y si de ello se obtienen ganancias cognoscitivas. El caso que he mostrado ofrecería una respuesta afirmativa, pero al tratarse de un objeto tan ilustre y con autores tan distinguidos, puede que el árbol que no nos deje ver todo el bosque. $\mathrm{Y}$ esto es un inconveniente.

Lo es porque no nos permite apreciar, como decía Bernard Stiegler, que solemos rechazar la técnica como objeto de pensamiento, experimentando una considerable opacidad con relación a ella. Y eso no es conveniente, porque necesitamos comprender ese proceso de evolución técnica, pues de lo contrario no intuiremos aquello que está realmente enjuego ni distinguiremos espontáneamente los procesos de transformación a largo plazo de otros acontecimientos más espectaculares y efímeros (STIEGLER, 2002: 41).

Es una desventaja, además, porque el entorno digital va mucho más allá de ejemplos como el mostrado, por muy significativo que sea. Vivimos en un mundo electrónico caracterizado por la abundancia y la desmaterialización, elementos que han acabado por ser indisociables y que han afectado al lugar y a la materia con los que hacemos la historia: el archivo y el documento (Pons, 2018b y c). Por supuesto, esos efectos no cubren las múltiples implicaciones del giro digital, dado que éste afecta a todas y cada una de las operaciones propias del campo histórico, de la profesión en suma (documentar, escribir, difundir, relacionarse, etcétera). Ahora bien, aunque haya muchos otros, los efectos fundamentales tienen que ver con el binomio archivo-documento, pues de allí procede nuestra credibilidad, de ahí obtenemos las credenciales que nos dan legitimidad como historiadores. Y, si son tan importantes, cualquier alteración afecta a todo el edificio.

Dicho eso, podemos volver sobre nuestros pasos. La mayor parte de las discusiones sobre la historia digital han sido de tipo metodológico, centradas sobre el uso de determinadas herramientas para revelar patrones en grandes conjuntos de fuentes textuales. Pero los cambios más profundos tienen que ver con lo que hacemos y con cómo lo hacemos. Es decir, muy pocos emplean herramientas cuantitativas, pero todos usan los nuevos buscadores y bases de datos de algún tipo, y el hecho de buscar y encontrar información de este modo tiene consecuencias significativas, al margen de que empleemos o no mapas, gráficos y estadísticas. 
Lo anterior no es una oda al nuevo mundo electrónico, sino una constatación, que es paso previo para comprender algunos de sus efectos. Como señaló Lara Putnam (2016), hay aspectos en todo ello que son muy importantes, aspectos en los que no reparamos porque no nos detenemos a reflexionar sobre las condiciones en las que trabajamos. Por ejemplo, dice Putman, hay una premisa general que ya fijó E. H. Carr, para quien los hechos o los datos no se parecen a «a los pescados en el mostrador del pescadero», sino más bien «a los peces que nadan en un océano anchuroso y aun a veces inaccesible, y lo que el historiador pesque dependerá en parte de la suerte, pero sobre todo de la zona del mar en que decida pescar y del aparejo que haya elegido, determinados desde luego ambos factores por la clase de peces que pretenda atrapar». En general, remataba Carr, «puede decirse que el historiador encontrará la clase de hechos que busca. Historiar significa interpretar» (CARR, 2017: 92). Es decir, utilizar un aparejo concreto, como las herramientas de búsqueda que ahora empleamos, transforma las condiciones que configuran la generación del conocimiento histórico.

De ese modo, y en primer lugar, la abundancia y la facilidad de acceso permiten formular hipótesis distintas, tal como proponen los citados Jo Guldi y David Armitage, sobre causas o procesos a gran escala. Pero la abundancia no debe hacernos olvidar que el universo del texto digitalizado no es representativo de la vida humana, sea del pasado o del presente. No solamente por la sobrerrepresentación del mundo anglófono en las fuentes digitalizadas, sino porque el presente, al igual que el pasado, suele registrarse enfatizando determinados fenómenos prominentes, haciendo que ciertas personas o grupos sean más visibles que otros. Pero el asunto fundamental, como nos recuerda Lara Putnam, es que la búsqueda de texto hace que la investigación esté radicalmente más descontextualizada. Por un lado, porque el motor de búsqueda nos devuelve sólo lo que buscamos, no su contexto. Si consultamos un periódico, podemos ir directamente al párrafo que contiene la palabra y obviar el resto de las noticias aparecidas ese día o esa semana o ese mes. Si es un documento lo que buscamos, acudir al archivo implicará consultar muchos distintos, advertir qué otros lo acompañan, comprender su organización, palparlo, olerlo, etcétera. Por otro, porque el mero hecho de acudir a un archivo, de visitar la ciudad en la que se halla y compartir rutinas o dudas con otros investigadores ofrece un contacto y una experiencia de los que el mundo digitalizado carece. Y la cuestión es que es un hecho casi irreversible. Sin el trabajo de campo, la investigación se puede hacer desde el escritorio, sin que nos veamos obligados a aventurarnos en lo material, sea la ciudad, el archivo o el documento físico, con la carga histórica de cada uno de ellos. Es decir, «el valor del trabajo de campo radica, entre otras cosas, en que hace que el investigador sea vulnerable a la historia. Cuando un investigador lee en una biblioteca, nadie lee lo que tiene detrás. Cuando lee en el campo, está constantemente guionizado, es objeto de una contra-observación y, por tanto, se ve forzado a enfrentarse no sólo a su localización geográfica, sino también a la histórica» (PURI, 2016, 40).

Por otra parte, no debemos olvidar otro tipo de limitaciones de la historia digital. Como reconocen muchos de sus impulsores, «aunque la computación pueda proporcionar un apoyo importante a un argumento histórico, rara vez ofrece la complejidad de la explicación que buscan los historiadores». Ello porque «pocas cuestiones históricas significativas pueden reducirse únicamente a una respuesta cuantitativa. Los argumentos históricos complejos sobre la causalidad 
y la experiencia suelen realizarse mediante múltiples tipos de análisis, inferencias sutiles, interpretación e interpolación» (ARGUING, 2017, 18-19).

En definitiva, y al margen de los problemas que plantea la práctica digital, lo cierto es que si no reflexionamos sobre los aparatos y los medios que nos rodean, no podremos advertir hasta qué punto afectan a nuestra vida y a nuestro quehacer académico. En pocas palabras, no es lo mismo la historia digital que lo digital en historia, y si bien lo primero es opcional, lo segundo no lo es, porque la desmaterialización y los algoritmos rigen gran parte de nuestras prácticas actuales y los historiadores necesitamos reflexionar y comprender el entorno digital en el que vivimos y trabajamos, un entorno que va más allá y del que difícilmente podemos escapar. Como dice Stiegler, «en la vida técnica, las condiciones de subsistencia vital así como de existencia social del individuo están constituidas de manera esencial por sus artefactos» (STIEGLER, 2012).

En efecto, en nuestro presente, el del mundo de la comunicación instantánea y de las redes sociales, de la desmaterialización del texto y de la abundancia, nuestras sociedades y los procesos en los que están envueltas no se pueden entender sin prestar atención a los procesos digitales que rigen nuestras vidas y nuestro trabajo. Si queremos dar sentido a esa masa crítica de datos, a esa cornucopia digital, debemos estar preparados, ser conscientes de sus implicaciones. Porque, en todo caso, investigar sin entender las nuevas tecnologías que sustentan esa investigación es un signo de complacencia, y la complacencia en historia o en humanidades es poco recomendable.

\section{REFERENCIAS}

Arguing (2017): «Arguing with Digital History working group», Digital History and Argument, white paper, Roy Rosenzweig Center for History and New Media (13/11/2017). Disponible en: https://rrchnm.org/argument-white-paper/ [consulta: 25 de junio de 2021].

Ayers, E.L. (1999): «The Pasts and Futures of Digital History». Disponible en: http:/ / www.vcdh.virginia.edu/PastsFutures.html [consulta: 25 de junio de 2021].

Berry, D. M. (2011): «The Computational Turn: Thinking About the Digital Humanities», Culture Machine, 12. Disponible en: https:/ / culturemachine.net/ wp-content/uploads/2019/01/10-Computational-Turn-440-893-1-PB.pdf. [consulta: 25 de junio de 2021].

BLANEY, J. et al. (2021): Doing digital history A beginner's guide to working with text as data, Manchester University Press, Manchester.

Brennan, T. (2017): «The Digital-Humanities Bust», The Chronicle of Higher Education, (15/10/2017). Disponible en: http://www.chronicle.com/article/The-Digital-Humanities-Bust/241424. [consulta: 25 de junio de 2021].

Boyd, D.; CRAWFord, K. (2012): «Critical Questions for Big Data - Provocations for a Cultural, Technological, and Scholarly Phenomenon», Information, Communication $\mathcal{E}$ Society, 15 (5): 662-679. https://doi.org/10.1080/136911 8X.2012.678878

Burrows, S. (2012): «The French Book Trade in Enlightenment Europe, 1769-1794: author's response», Reviews In History, 1355. Disponible en: http:/ / www.history.ac.uk/reviews/review/1355. [consulta: 25 de junio de 2021]. 
Burrows, S. (2015): «Charmet and the book police: clandestinity, illegality and popular reading in late Ancien Régime France», French History and Civilisation: Papers from the George Rudé Seminar, 6: 32-55. Disponible en: https://h-france.net/rude/wp-content/uploads/2017/08/BurrowsVol6.pdf. [consulta: 25 de junio de 2021].

Burrows, S.: (2017a): «Forgotten Best-Sellers of Pre-Revolutionary France», French History and Civilisation: Papers from the George Rudé Seminar,7: 51-65. Disponible en: https://h-france.net/rude/wp-content/uploads/2017/08/vol7_ Burrows.pdf [consulta: 25 de junio de 2021].

Burrows, S. (2017b) «Omissions and Revisions in Enlightenment Book History: A Rejoinder to Robert Darnton», French History and Civilisation: Papers from the George Rudé Seminar, 7: 209-217. Disponible en: https://h-france.net/rude/ wp-content/uploads/2017/08/vol7_Burrows_response.pdf [consulta: 25 de junio de 2021].

Burrows, S. (2018): The French Book Trade in Enlightenment Europe, II. Enlightenment Bestsellers, Bloomsbury, London.

Burrows, S. et al., (2016): «Mapping Print, Connecting Cultures», Library $\mathcal{E}$ Information History, 32, 4: 259-271. https://doi.org/10.1080/17583489.2016.1 220781

CARr, E.H. (2017): ¿Qué es la Historia?, Planeta, Barcelona.

Crymble, A. (2021): Technology and the historian : transformations in the digital age Responsibility, University of Illinois Press, Urbana.

Curran, M. (2013): «Beyond The Forbidden Best-Sellers of Pre-Revolutionary France», The Historical Journal, 56 (1): 89-112. https://doi.org/10.1017/ S0018246X12000556

Curran, M. (2018) The French Book Trade in Enlightenment Europe, I. Selling Enlightenment. Bloomsbury, London.

Dacos, M. (2011): Manifiesto por unas Humanidades Digitales, (2/4/2011). Disponible en: https:/ / tcp.hypotheses.org/487 [consulta: 25 de junio de 2021].

Darnton, R. (2006): El negocio de la Ilustración: historia editorial de la Encyclopédie, 1775-1800, FCE, México.

DARNTON, R. (2008): Los best sellers prohibidos en Francia antes de la Revolución, FCE, Buenos Aires.

DARnTON, R. (2010), Las razones del libro: Futuro, presente y pasado, Trama Editorial, Madrid.

DARnTON, R. (2012): «The French Book Trade in Enlightenment Europe, 17691794», Reviews in History, 1355. Disponible en: http:/ / www.history. ac.uk/ reviews/review/1355 [consulta: 25 de junio de 2021].

Darnton, R. (2015a): A Literary Tour de France: Publishing and the Book Trade in France and Francophone Europe, 1769-1789. Disponible en: https://wayback. archive-it.org/5488/20210325115631/http://robertdarnton.org/ [consulta: 25 de junio de 2021].

DARNTON, R. (2015b): «The Demand for Literature in France, 1769-1789, and the Launching of a Digital Archive», The Journal of Modern History, 87 (3): 509-531. https:// doi.org/10.1086/682412.

DARnton, R. (2017) «Diffusion and Confusion in the Study of Enlightenment», French History and Civilisation: Papers from the George Rudé Seminar,7: 204-208. Disponible en: https://h-france.net/rude/wp-content/uploads/2017/08/ vol7_Darnton.pdf [consulta: 25 de junio de 2021]. 
DARnton, R. ( 2018): A Literary Tour de France. The World of Books on the Eve of the French Revolution, Oxford University Press, Oxford.

Darnton, R. (2021): Pirating and Publishing. The Book Trade in the Age of Enlightenment, Oxford University Press, Oxford.

Fiormonte, D. (2017): «The Digital Humanities from Father Busa to Edward Snowden», Media Development, 64 (2): 29-33.

FISH, S. (2012): «Mind Your P's and B's: The Digital Humanities and Interpretation», Nytimes.com (23/1/2012). Disponible en: http://opinionator.blogs. nytimes.com/ 2012/01/23/mind-your-ps-and-bs-the-digital-humanities-and-interpretation/ [consulta: 25 de junio de 2021].

FRENCH (2012): FBTEE: The French Book Trade in Enlightenment Europe Mapping the Trade of the Société Typographique de Neuchâtel, 1769-1794. Disponible en: http:/ / fbtee.uws.edu.au/main/ [consulta: 25 de junio de 2021].

GinZBURG, C. (2004): "Correspondencia. Entrevista», DC papers. Revista de crítica y teoría de la arquitectura, 12 (2004): 19-27.

GinZBurG, C. (2013): «Nuestras palabras y las suyas. Una reflexión sobre el Oficio de Historiador, hoy», Contrahistorias, 19: 7-24.

Graham, S. et al. (2015): Exploring Big Historical Data. The Historian's Macroscope, Imperial College Press, London.

Guldi, J.; Armitage, D. (2014): Manifiesto por la historia, Alianza, Madrid.

Guld, J. (2020): «The common landscape of digital history: Universal methods, global borderlands, longue-durée history, and critical thinking about approaches and institutions», en M. Fridlund, M. Oivay y P. Paju (eds.), Digital histories: Emergent approaches within the new digital history, Helsinki University Press, Helsinki: 327-346. https:/ / doi.org/10.33134/HUP-5-18.

Hiтснсоск, T. (2016): «The Digital Humanities in Three Dimensions», en Historyonics Blog. Disponible en: http:/ / historyonics.blogspot.com/2016/07/the-digital-humanities-in-three.html [consulta: 25 de junio de 2021].

Kirschenbaum, M.G. (2012): «What Is Digital Humanities and What's It Doing in English Departments ?», en M. K. Gold (ed.), Debates in the Digital Humanities, University of Minnesota Press, Minneapolis: 3-11. Disponible en: https:// dhdebates.gc.cuny.edu/projects/debates-in-the-digital-humanities [consulta: 25 de junio de 2021].

Latour, B. (2009): «Tarde's idea of quantification», en M. Candea (ed.), The Social After Gabriel Tarde: Debates and Assessments, Routledge, London: 145-162.

Manning, P. (2013): Big Data in History, Palgrave McMillan, New York.

MAyer-SchÖNBERGER, V.; CUKIER, K. (2013): Big Data A Revolution That Will Transform How We Live, Work and Think, Houghton Mifflin Harcourt, New York.

McGanN, J. (2013): «Information Technology and the Troubled Humanities», en M. Terras, J. Nyhan y E. Vanhoutte (eds.), Defining Digital Humanities. A Reader, Ashgate, Farnham: 49-65.

McGann, J. (2014): A New Republic of Letters. Memory and Scholarship in the Age of Digital Reproduction, Harvard University Press, Cambridge, Mass.

MoretTI, F. (2000): «Conjeturas sobre la literatura mundial», New Left Review, 3: 65-76.

Moretti, F. (2016): «The Digital in the Humanities: An Interview with Franco Moretti», Los Angeles Review of Books, (2/02/2016). Disponible en: https:/ / lareviewofbooks.org/article/the-digital-in-the-humanities-an-interview-with-franco-moretti/ [consulta: 25 de junio de 2021]. 
Moretti, F. (2017): «Patterns and Interpretation», Pamphlets of the Stanford Literary Lab, 15. Disponible en: https:/ / litlab.stanford.edu/LiteraryLabPamphlet15. pdf [consulta: 25 de junio de 2021].

Mounier, P. (2018): Les humanités numériques: Une histoire critique, Éditions de la Maison des sciences de l'homme, Paris. https:// doi.org/10.4000/books.editionsmsh.12006.

PONS, A. (2018a): «El pasado fue analógico, el futuro es digital. Nuevas formas de escritura histórica», Ayer, 110: 19-50.

PONS, A. (2018b): «La sensibilidad digital y la posición del historiador», en M. Eiroa (coord..), Historia y memoria en Red: un nuevo reto para la historiografía, Síntesis, Madrid: 21-40.

Pons, A. (2018c): «La memoria digital del mundo. Los historiadores y el archivo», Tabula: revista de archivos de Castilla y León, 21: 23-40

Puri, S. (2016): «Finding the Field: Notes on Caribbean Cultural Criticism, Area Studies, and the Forms of Engagement», en S. Puri y D. CASTILlo (eds.), Theorizing Fieldwork in the Humanities, Palgrave Macmillan, New York: 29-49.

PutNAM, L. (2016): «The Transnational and the Text-Searchable: Digitized Sources and the Shadows They Cast», The American Historical Review, 121 (2): 377-402.

Robertson, S. (2016): «The Differences between Digital Humanities and Digital History», en L.F. KLEIN y M.K. Gold, (eds.), Debates in the Digital Humanities, University of Minnesota Press, Minneapolis. Disponible en: http:/ / dhdebates.gc.cuny.edu/debates/text/76 [consulta: 25 de junio de 2021].

SCHEINFELDT, T. (2014): «The Dividends of Difference: Recognizing Digital Humanities' Diverse Family Tree/s», en Found History Blog (7/04/2014). Disponible en: http:/ / foundhistory.org/2014/04/the-dividends-of-difference-recognizing-digital-humanities-diverse-family-trees/ [consulta: 25 de junio de 2021].

Runia, E, (2014): Moved by the Past: Discontinuity and Historical Mutation, Columbia UP, Nueva York.

Salmi, H. (2020): What is Digital History?, Polity Press, Cambridge.

Schreibman, S.; Siemens, R.R.; Unsworth, J. (eds.), A Companion to Digital Humanities, Blackwell, Oxford. Disponible en: http://www.digitalhumanities.org/ companion/ [consulta: 25 de junio de 2021].

Stiegler, B. (2002): La técnica y el tiempo I. El pecado de Epimeteo, Hiru, Hondarribia. StiegleR, B. (2012) «Appel aux études digitales (Entretiens du Nouveau Monde Industriel. 2012)». Disponible en: https://digital-studies.org/wp/appel-aux-etudes-numeriques/ [consulta: 25 de junio de 2021].

Thomas III, W. G. (2008), en D.J. Cohen, M. Frisch, P. Gallagher, S. Mintz, K. Sword, A. Murrell Taylor, W.G. Thomas III y W.J. Turkel, «Interchange: The Promise of Digital History», The Journal of American History, 95 (2): 442-491.

Unsworth, J. (2013): «What is Humanities Computing and What is Not?», en M. Terras, J. Nyhan y E. Vanhoutte (eds.), Defining Digital Humanities. A Reader, Ashgate, Farnham: 35-48.

Winters, J. (2018): «Digital History», en M. TAmm y P. Burke (eds.), Debating New Approaches to History, Bloomsbury Academic, London: 277-300. 
